\title{
Anion- $\pi$ Catalysis of Enolate Chemistry: Rigidified Leonard Turns as a General Tool to Run Reactions on Aromatic Surfaces
}

\author{
Yoann Cotelle, ${ }^{[a, b]}$ Sebastian Benz, ${ }^{[a, b]}$ Alyssa-Jennifer Avestro, ${ }^{[a, c, d]}$ Thomas R. Ward, ${ }^{[e]}$ Naomi Sakai ${ }^{[a]}$ \\ and Stefan Matile ${ }^{[a]_{*}}$
}

\begin{abstract}
To integrate anion- $\pi$, cation- $\pi$ and ionpair- $\pi$ interactions in catalysis, the fundamental challenge is to run reactions reliably on aromatic surfaces. Addressing a specific question concerning enolate addition to nitroolefins, this study elaborates on Leonard turns to tackle this problem in a general manner. Increasingly refined turns are constructed to position malonate half thioesters as close as possible on $\pi$-acidic surfaces. The resulting preorganization of reactive intermediates is shown to support the disfavored addition to enolate acceptors to an absolutely unexpected extent. This decisive impact on anion- $\pi$ catalysis increases with the rigidity of the turns. The new, rigidified Leonard turns are most effective with weak anion-m interactions, while stronger interactions do not require such ideal substrate positioning to operate well. The stunning simplicity of the motif and its surprisingly strong relevance for function promises general usefulness of the introduced approach.
\end{abstract}

Rien ne sert de courir ; il faut partir à point. Le Lièvre et la Tortue en sont un témoignage.

Thus begins Jean de La Fontaine (1621-1695 AD) to recount the ancient Greek fable from Aesop (620-560 BC). The result is known. In the context of chemical transformations, Aesop's fable perfectly describes the challenge to selectively catalyze a disfavored reaction. A most intriguing example for "tortoise-andhare" catalysis occurs at the beginning of the biosynthesis of most natural products and is repeated most impressively in the polyketide pathway. ${ }^{[1]}$ Malonyl-CoA, a malonic acid half thioester (MAHT), has evolved as the substrate of choice to accomplish the involved enolate chemistry under biological conditions. However, without enzymes under unoptimized conditions in solution, the addition of the conjugate bases of MAHTs such as 1a, i.e., the malonate half thioesters (MHTs), to enolate acceptors such as nitroolefin 2 to cleanly generate the relevant addition product $\mathbf{3 a}$ fails (Figure 1 ) ${ }^{\left[{ }^{[2]}\right.}$ Instead, decarboxylation is

[a] Dr. Y. Cotelle, S. Benz, Dr. A.-J. Avestro, Dr. N. Sakai, Prof. S. Matile Department of Organic Chemistry

National Centre of Competence in Research (NCCR) Molecular

Systems Engineering

University of Geneva, Geneva, Switzerland

Fax: (+) 41223793215

E-mail: stefan.matile@unige.ch

Homepage: www.unige.ch/sciences/chiorg/matile/

[b] These two authors contributed equally to this study.

[c] Dr. A.-J. Avestro

Department of Chemistry, Northwestern University, Evanston IL, USA

[d] Current address: Department of Chemistry, University of Durham, Durham, United Kingdom

[e] Prof. T. R. Ward

Department of Chemistry, NCCR Molecular Systems Engineering University of Basel, Basel, Switzerland

Supporting information for this article is given via a link at the end of the document. the favored reaction, leading to the less useful thioester $4 \mathbf{a}$ as the major product. Several elegant solutions have been developed to tame the capricious MHT anions, including bioinspired approaches to asymmetric enolate addition to various acceptors. $^{[3]}$

a)

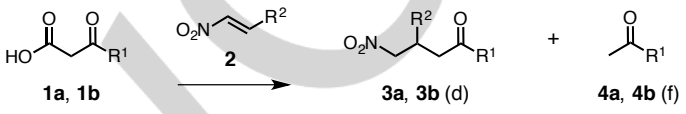

b)

d) addition $\uparrow \quad$ decarboxylation $\uparrow$

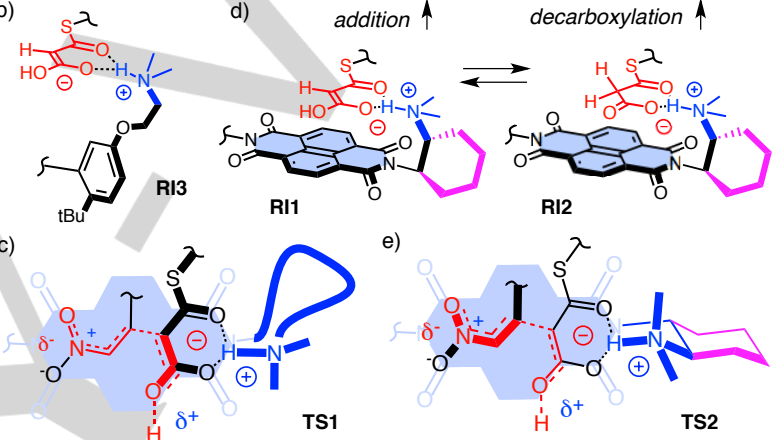

Figure 1. a) Addition of MAHTs $1 \mathrm{a}\left(\mathrm{R}^{1}=\mathrm{SPMP}, \mathrm{PMP}=p\right.$-methoxyphenyl) or $\beta$-keto acids $1 \mathbf{b}\left(R^{1}=P h\right)$ to nitroolefins $2\left(R^{2}=P h\right)$, forming disfavored $(d)$ addition products $\mathbf{3 a} / \mathbf{3} \mathbf{b}$ or the favored (f) decarboxylation products $\mathbf{4 a} / \mathbf{4 b}$. b) The original $m$-phenyl turns place the enolate tautomer far from the $\pi$ surface. c) "Top-down" addition of remote enolates (RI3) to nitroolefins on the $\pi$ surface. d) Fixed (magenta) Leonard turns should place MHTs close to the $\pi$ surface to influence the equilibrium between MHT tautomers. e) "Bottom-up" addition of enolates on the $\pi$ surface (RI1) to nitroolefins far from the $\pi$ surface.

Complementary to the more common cation- $\pi$ interactions on $\pi$-basic aromatic surfaces, ${ }^{[4]}$ anion- $\pi$ interactions occur on $\pi-$ acidic surfaces. Their existence has been proposed by theoreticians a bit more than a decade ago and verified experimentally to occur in solid, solution and gas phase..$^{[5,6]}$ Functional relevance of anion- $\pi$ interactions has been demonstrated for self-assembly, ${ }^{[7]}$ transport $^{[8,9]}$ and, most recently, also for catalysis. ${ }^{[2,10,11]}$ In this context, the selective acceleration of the disfavored addition of MAHT 1a to nitroolefins 2 has been realized $^{[2]}$ in the presence of naphthalenediimides (NDIs). ${ }^{[10,12]}$ Their $\pi$-acidic surface has been introduced as ideal for differentiating between planar MHT tautomers with delocalized charges (as in reactive intermediate RI1, Figure 1d) and deplanarized tautomers with charges localized on the carboxylate (as in RI2). This discrimination was expected to differently influence the energy of the transition states leading to enolate addition and decarboxylation and thus to control the selectivity of the reaction. However, in our original design, the catalytic amine was positioned quite far from the $\pi$ surface. Ion pairing to the conjugate ammonium cation should also remove the MHT anion from this surface (RI3, Figure $1 \mathrm{~b}$ ), enabling the nitroolefin acceptor 2 on the $\pi$ surface to be approached by the MHT from above or "top-down" (transition state TS1, Figure 1c). This architecture should thus provide 


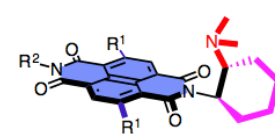<smiles>C[I-]1CCCC12CCO2</smiles>
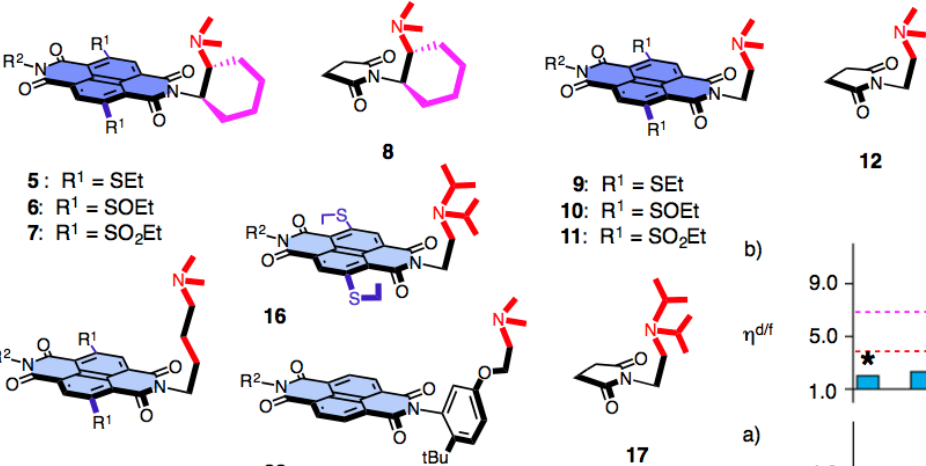

9: $R^{1}=S E$

10: $R^{1}=S O E t$

11: $\mathrm{R}^{1}=\mathrm{SO}_{2} \mathrm{Et}$

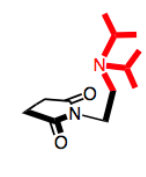

13: $R^{1}=S E t$

14: $R^{1}=S O E t$

15: $\mathrm{R}^{1}=\mathrm{SO}_{2} \mathrm{Et}$

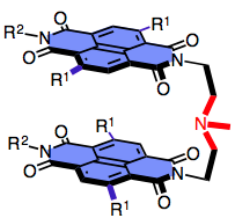

17
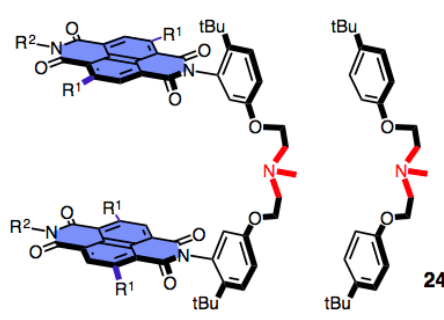

a)

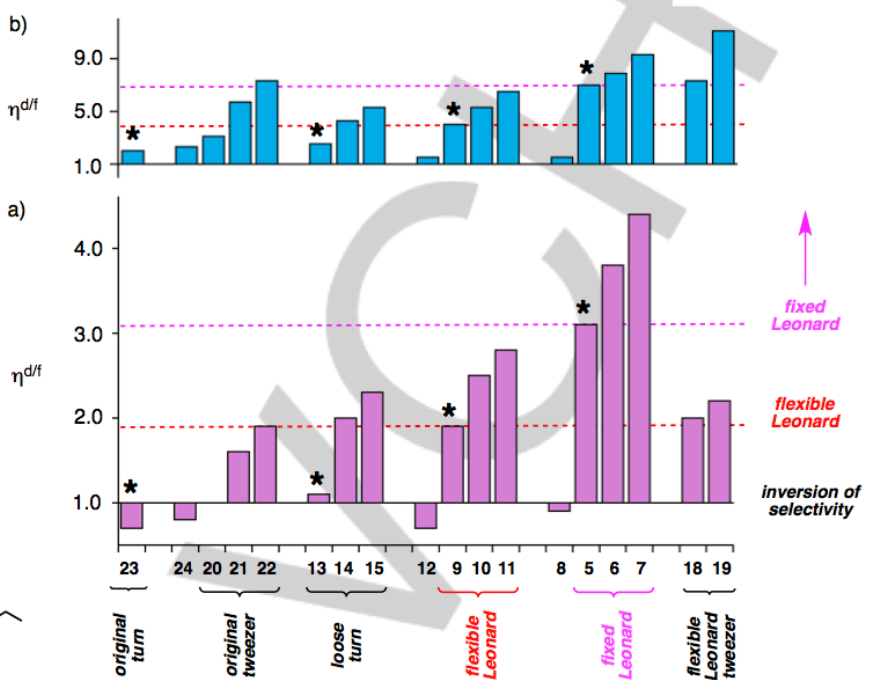

Figure 2. a) Catalyst selectivity $\eta^{\mathrm{d} / \mathrm{f}}=\eta^{\mathrm{d}} / \eta^{\mathrm{f}}$, i.e. the yield $\eta^{\mathrm{d}}$ of the intrinsically disfavored product (3a) divided by the yield $\eta^{\mathrm{f}}$ of the favored product (4a) in the presence of catalysts $5-24$ in THF- $d_{8}$ at $20^{\circ} \mathrm{C}$. b) Same at $7{ }^{\circ} \mathrm{C}$ for $3 \mathbf{a}$ and $\mathbf{4 a}$. c) Same at $7{ }^{\circ} \mathrm{C}$ for $\mathbf{3 b}$ and $\mathbf{4 b}$. All sulfoxides are isolated as mixtures of stereoisomers. See Table 1 for exact values and conditions. *Most important trends with comparable structures. ${ }^{* *}$ Not measured.

excellent stabilization of nitronate intermediates by anion-m interactions albeit having minimal influence on the equilibrium between MHT tautomers, i.e., resulting in poor selectivity. The objective of the present study was to develop general design strategies to enhance selectivity by (i) moving the MHT substrates as close as possible to the $\pi$ surface (Figure 1d), i.e., to have the enolate approach to nitroolefin from below or "bottom-up," and (ii) allowing the nitronate reach the $\pi$ surface only upon its formation during enolate addition (TS2, Figure 1e). The significance of the results described herein suggests that the newly introduced, rigidified Leonard turns ${ }^{[13]}$ represents a general design principle for enabling reactions to occur on aromatic surfaces and thus harnessing the full potential of anion$\pi,{ }^{[2,5-8,10,11]}$ cation- $\pi^{[4]}$ and ionpair- $\pi$ interaction ${ }^{[9]}$ for catalysis.

The new catalysts and controls 5-19 were designed and synthesized based on lessons learned from the original catalysts 20-24 (Figure 2). Complete details on synthesis and evaluation under standard conditions can be found in the Supporting Information (SI). Anion- $\pi$ catalyst 9 was conceived as starting point for our systematic study. Kept as simple as possible, it contains a single NDI surface with two ethylsulfide substituents as a handle to tune $\pi$ acidity $\left(R^{1}\right),{ }^{[14]}$ an L-leucyl- $n$-hexylamide tail to ensure solubility $\left(R^{2}\right)$, and a Leonard turn in its purest form.

Introduced almost fifty years ago ${ }^{[13]}$ as trimethylene chains, Leonard turns can be considered more generally as three tetrahedral atoms that are in a half-chair conformation and continue with an aromatic surface at one end. The first atom following at the other end will find itself at very short distance literally forced on top of the ipso atom of the aromatic ring. Leonard turns have been used extensively in functional systems, often not explicitly. ${ }^{[6,9,11,15]}$ In catalyst 9 , the Leonard turn consists of two methylenes and the $s p^{3}$ nitrogen of the amine base. ${ }^{[6]}$ The proton transferred to this nitrogen should then end up at short distance above the imide nitrogen of the NDI, which in turn should place the MHT carbonyls at the positive end of the imide carbonyls, in line with the bonds leading to the naphthalene core (Figures 1d, e).

In view of these considerations, we were delighted to find that, under routine conditions at $20^{\circ} \mathrm{C},{ }^{[2]}$ our first Leonard catalyst 9 catalyzed the addition of MAHT 1a to nitroolefin 2 selectively: The intrinsically disfavored (d) addition product 3 a was obtained in $\eta^{d}=65 \%$ yield, with the naturally more favored (f) decarboxylation product 4 a generated in $\eta^{\dagger}=34 \%$ (Table 1 , entry 5). The resulting selectivity $\eta^{\mathrm{d} / \mathrm{f}}=1.9$ was outstanding considering that the original catalyst $\mathbf{2 3}$ with a loose turn failed to cause the desired selectivity inversion $\left(\eta^{\mathrm{d} / \mathrm{f}}=0.8\right.$, Figure $2 \mathrm{a}^{*}$, Table 1 , entry 19). The new Leonard catalyst $\mathbf{9}$, as simple as it gets, was already as good as the most developed original tweezer catalyst 22, with two NDIs next to the amine and two sulfones in the NDI core maximize effective molarity and $\pi$ acidity, respectively (Figure $2 a$, Table 1 , entry 18). Increasing selectivity upon oxidation of the sulfides in the core of 9 to sulfoxides in 10 and sulfones in $11\left(\eta^{\mathrm{d} / \mathrm{f}}=2.5\right.$ and 2.8$)$ and the absence of selectivity inversion with control 12 without $\pi$ surface $\left(\eta^{\mathrm{d} / \mathrm{f}}=0.7\right)$ evinced operational anion- $\pi$ interactions in the presence of Leonard turns (Figure 2a, Table 2, entries 5-8).

Control 13 with a loose tetramethylene turn failed to perform as good as Leonard catalyst 9 (Figure $2 a^{*}$ ). However, increasing selectivity inversion with increasing $\pi$ acidity in 13-15 revealed the existence of tortoise-and-hare anion- $\pi$ catalysis also with looser turns (Table 1, entries 9-11). Control 16 with a bulky Hünig base analog in the Leonard turn performed only slightly better than control 17 without $\pi$ surface $\left(\eta^{\mathrm{d} / \mathrm{f}}=0.9 \mathrm{vs} \eta^{\mathrm{d} / \mathrm{f}}=0.7\right.$, Table 1, entry 12-13), presumably because the steric crowding hinders operational anion- $\pi$ interactions. Inreasing the effective 
molarity of $\pi$ surfaces in tweezer-like Leonard catalysts 18-19 did not improve the outstanding activity of the most simple, most compact monomeric Leonard catalysts 9-11 (Figure 2, Table 1, entries $14-15$ vs $5-7$ ).

Table 1. Characteristics of Anion- $\pi$ Catalysts and Controls. ${ }^{[a]}$

\begin{tabular}{|c|c|c|c|c|c|c|c|}
\hline & $\mathrm{C}^{[\mathrm{b}]}$ & $\begin{array}{c}\pi \\
\text { acidity }^{[c]}\end{array}$ & $S^{[d]}$ & $\begin{array}{l}\eta^{\mathrm{d} / I} \\
\%^{[e]}\end{array}$ & $\begin{array}{l}\eta^{f / /} \\
\%^{[f]}\end{array}$ & $\eta^{\mathrm{dff}[g]}$ & $\begin{array}{r}\Delta \Delta G_{\mathrm{TS}}{ }^{[1]} \\
\mathrm{kJ} \mathrm{mol}^{-1[h]}\end{array}$ \\
\hline 1 & 5 & + & $1 a$ & $84(74)$ & $12(24)$ & $7.0(3.1)$ & $-3.6(-3.0)$ \\
\hline 2 & 6 & ++ & $1 a$ & $87(77)$ & $11(20)$ & $7.9(3.8)$ & $-3.9(-3.5)$ \\
\hline 3 & 7 & +++ & $1 a$ & $86(80)$ & $9(18)$ & $9.6(4.4)$ & $-4.3(-3.9)$ \\
\hline 4 & 8 & - & $1 a$ & $57(47)$ & $39(52)$ & $1.5(0.9)$ & - \\
\hline 5 & 9 & + & $1 a$ & $78(65)$ & $19(34)$ & $4.1(1.9)$ & $-2.3(-2.3)$ \\
\hline 6 & 10 & ++ & $1 a$ & $80(68)$ & $15(27)$ & $5.3(2.5)$ & $-2.9(-2.9)$ \\
\hline 7 & 11 & +++ & $1 a$ & $84(74)$ & $13(26)$ & $6.5(2.8)$ & $-3.4(-3.4)$ \\
\hline 8 & 12 & - & $1 a$ & $59(43)$ & $40(56)$ & $1.5(0.7)$ & - \\
\hline 9 & 13 & + & $1 a$ & $70(50)$ & $28(47)$ & $2.5(1.1)$ & $-1.2(-1.1)$ \\
\hline 10 & 14 & ++ & $1 a$ & $81(64)$ & $19(32)$ & $4.3(2.0)$ & $-2.4(-2.6)$ \\
\hline 11 & 15 & +++ & $1 a$ & $83(68)$ & $16(30)$ & $5.2(2.3)$ & $-2.9(-2.9)$ \\
\hline 12 & 16 & + & $1 a$ & $73(43)$ & $25(48)$ & $2.9(0.9)$ & $-1.5(-0.6)$ \\
\hline 13 & 17 & - & $1 a$ & (40) & (54) & $(0.7)$ & - \\
\hline 14 & 18 & + & $1 a$ & $87(51)$ & $12(23)$ & $7.3(2.0)$ & $-3.7(-2.6)$ \\
\hline 15 & 19 & ++ & $1 a$ & $89(54)$ & $8(27)$ & $11.1(2.2)$ & $-4.6(-3.4)$ \\
\hline 16 & 20 & + & $1 a$ & $71(50)$ & $23(48)$ & $3.1(1.0)$ & $-1.2(-0.9)$ \\
\hline 17 & 21 & ++ & $1 a$ & $80(59)$ & $14(36)$ & $5.7(1.6)$ & $-2.9(-2.0)$ \\
\hline 18 & 22 & +++ & $1 a$ & $80(59)$ & $11(31)$ & $7.3(1.9)$ & $-3.5(-2.6)$ \\
\hline 19 & 23 & + & $1 a$ & $69(46)$ & $30(54)$ & $2.3(0.8)$ & $-0.7(-0.8)$ \\
\hline 20 & 24 & - & $1 a$ & $60(37)$ & $30(53)$ & $2.0(0.7)$ & - \\
\hline 21 & 5 & + & $1 b$ & 65 & 34 & 1.9 & -2.3 \\
\hline 22 & 7 & +++ & $1 b$ & 74 & 25 & 3.0 & -3.4 \\
\hline 23 & 9 & + & $1 b$ & 59 & 41 & 1.4 & -1.6 \\
\hline 24 & 10 & ++ & $1 b$ & 64 & 33 & 1.9 & -2.3 \\
\hline 25 & 11 & +++ & $1 b$ & 68 & 32 & 2.1 & -2.6 \\
\hline 26 & 12 & - & $1 b$ & 42 & 57 & 0.7 & - \\
\hline
\end{tabular}

[a] Reactions were conducted in THF- $d_{8}$ with $20 \mathrm{~mol} \%$ catalyst and monitored by ${ }^{1} \mathrm{H}$ NMR spectroscopy. [b] Catalysts, see Figure 2 for structures. [c] Qualitative indication for increasing $\pi$ acidity, - = no $\pi$ surface. [d] Substrates; 1a: $200 \mathrm{mM}$ with $2 \mathrm{M} \mathrm{2;} \mathrm{1b}$ $200 \mathrm{mM}$ with $1.5 \mathrm{M} \mathrm{2}$. [e] Yield of intrinsically disfavored products $3 a / 3 b$ in THF at $7^{\circ} \mathrm{C}$ (in parenthesis: $\eta^{\mathrm{d}}$ at $20^{\circ} \mathrm{C}$ ). [f] Yield of the intrinsically favored products $4 \mathbf{a} / \mathbf{4 b}$ at $7{ }^{\circ} \mathrm{C}$ $\left(20^{\circ} \mathrm{C}\right)$. [g] Selectivity $\eta^{\mathrm{d} / \mathrm{f}}=\eta^{\mathrm{d}} / \eta^{\mathrm{f}}$ at $7^{\circ} \mathrm{C}\left(20^{\circ} \mathrm{C}\right)$. [h] Selective catalysis: The difference in Gibbs free energy $\Delta G_{\mathrm{TS}}{ }^{\ddagger}$ (catalyst) of the two transition states leading to intrinsically favored (f) and disfavored (d) reaction, calibrated against the nearest control $\Delta G_{\mathrm{TS}}{ }^{\ddagger}(\mathbf{8}, 12,17,24) ; \Delta G_{\mathrm{TS}}{ }^{\ddagger}=-R 7 \mathrm{nn}\left(\eta^{\mathrm{d} / \mathrm{f}}\right),{ }^{[16]} \Delta \Delta G_{\mathrm{TS}}{ }^{\ddagger}=\Delta G_{\mathrm{TS}}{ }^{\ddagger}$ (catalyst) $-\Delta G_{\mathrm{TS}^{\ddagger}}{ }^{\ddagger}$ (control). Data for 20-24 are from ref [2].

In catalyst $\mathbf{5}$, the flexible Leonard turn of catalyst $\mathbf{9}$ is rigidified (see TS2 in Figure 1e). In doing so, selectivity inversion increased to $\eta^{\mathrm{d} / \mathrm{f}}=3.1$ (Table 1 , entry 1 ). Increasing $\pi$ acidity in catalysts 6 and 7 further improved activity to $\eta^{\mathrm{d} / \mathrm{f}}=3.8$ and $\eta^{\mathrm{d} / \mathrm{f}}=$ 4.4 (Table 1, entries 2, 3). The $\eta^{\mathrm{d} / \mathrm{f}}=0.9$ for control 8 without $\pi$ surface confirmed that these quite spectacular results originate from maximizing anion- $\pi$ interactions with the rigidified Leonard turn in catalysts 5-7. Comparison over the full series of comparable architectures from original and loose turns in $\mathbf{2 3}\left(\eta^{\mathrm{d} / \mathrm{f}}\right.$
$=0.8)$ and $13\left(\eta^{\mathrm{d} / \mathrm{f}}=1.1\right)$ to flexible Leonard turns in $9\left(\eta^{\mathrm{d} / \mathrm{f}}=1.9\right)$ beautifully illustrate the unique power of fixed Leonard turns in $\mathbf{5}$ $\left(\eta^{\mathrm{d} / \mathrm{f}}=3.1\right)$ to run reactions on $\pi$ surfaces and maximize contributions from anion- $\pi$ interactions to catalysis (Figure 2a*). The same trend holds true at maximal $\pi$ acidity, moving from $\eta^{\mathrm{d} / \mathrm{f}}$ $=2.3$ for loose turns in 15 to $\eta^{\mathrm{d} / \mathrm{f}}=2.8$ with flexible Leonard turns in 9 and $\eta^{\mathrm{d} / \mathrm{f}}=4.4$ with fixed Leonard turns in 7 .

Reactions run at $7^{\circ} \mathrm{C}$ instead of $20^{\circ} \mathrm{C}$ gave overall the same trends (Figure 2b). For example, the steady increase from original and loose turns in $23\left(\eta^{\mathrm{d} / \mathrm{f}}=2.3\right)$ and $13\left(\eta^{\mathrm{d} / \mathrm{f}}=2.5\right)$ to flexible Leonard turns in $9\left(\eta^{\mathrm{d} / \mathrm{f}}=4.1\right)$ and fixed Leonard turns in $5\left(\eta^{\mathrm{d} / \mathrm{f}}=7.0\right)$ remained intact (Figure $\left.2 \mathrm{a}^{*}\right)$. Overall higher selectivity was consistent with the notion of strengthened anion$\pi$ interactions at lower temperatures. In this instance, the impact of flexible as well as fixed Leonard turns was less pronounced, whereas the effective molarity of $\pi$ surfaces became more important. For example, loose tweezers 22 at maximal $\pi$ acidity reached the selectivity of fixed Leonard turns 5 at minimal $\pi$ acidity (Figure $2 \mathrm{~b}$ ); at $20^{\circ} \mathrm{C}, \mathbf{2 2}$ was clearly less active than $\mathbf{5}$ (Figure 2a). Moreover, the overall best performance was found for tweezers 19 with flexible Leonard turns and intermediate $\pi$ acidity $\left(\eta^{\mathrm{d} / \mathrm{f}}=11.1\right)$, although the fixed Leonard turns in monomeric 7 were almost as good $\left(\eta^{\mathrm{d} / \mathrm{f}}=9.3\right.$, Figure $\left.2 \mathrm{~b}\right)$; at 20 ${ }^{\circ} \mathrm{C}$, 19 was much less active than 7 , also 5 (Figure 2a). This overall reduced importance at lower temperature suggested that the contributions from flexible and, in particular, fixed Leonard turns are mainly entropic, i.e., a most practical and most significant expression of the classical concept of preorganization.

It has been established previously ${ }^{[2]}$ that a combination of selective deceleration of the intrinsic decarboxylation in favor of accelerating the disfavored addition gives rise to the observed inversion of selectivity. These most intriguing trends were expected to emerge from the ability of anion- $\pi$ interactions to distinguish the planar MHT enolate as in RI1 from the nonplanar malonate tautomer as in RI2 (Figure 1d). Assuming a Curtin-Hammett situation where the two classes of tautomers are in rapid equilibrium, the difference in Gibbs free energy $\Delta G_{\mathrm{TS}}{ }^{\ddagger}$ of the two transition states leading to addition (d) or decarboxylation (f) is determined by the ratio $d / f$ of the products (Table 1). ${ }^{[16]}$ The resulting $\Delta G_{\mathrm{TS}}{ }^{\ddagger}$ of the catalysts were then calibrated against the background contributions of amine bases without nearby $\pi$-acidic surface. The dependence of the obtained $\Delta \Delta G_{\mathrm{TS}}{ }^{\ddagger}$ (Table 1) on $\pi$ acidity was roughly linear for fixed Leonard turns in 5-7 $(\diamond)$, flexible Leonard turns in 9-11 (घ) and loose turns in 13-15 catalysts (Figure 3, O). The slopes, however, were clearly different. This difference, i.e., steeper slopes for less preorganizing turns, provided corroborative experimental evidence that the significance of flexible and particularly fixed Leonard turns increases with decreasing $\pi$ acidity. This finding was consistent with the increasing importance of Leonard turns observed with increasing temperature (Figure 2a vs $2 b$ ). Therefore, it can be concluded that precisely engineered turns enable efficient anion- $\pi$ catalysis to take place even with relatively weak $\pi$ acidity. If the aromatic surface is strongly electron deficient, anion- $\pi$ catalysis takes place efficiently even when substrate placement (i.e., the constituent nature of the Leonard link) is less than ideal. 


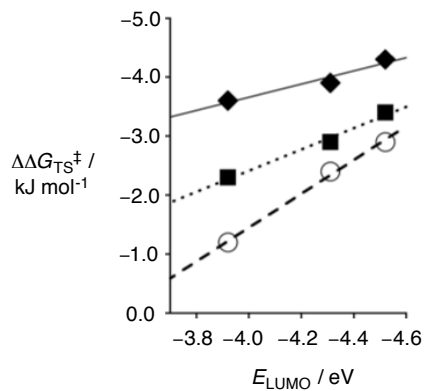

Figure 3. Differential transition-state stabilization $\Delta \Delta G_{\mathrm{TS}}{ }^{\ddagger}$ for $\mathbf{5 - 7}(\boldsymbol{\nabla}$, vs 8) $\mathbf{9}$ $11(\square$, vs 12$)$ and 13-15 (O, vs 12) as a function of the LUMO energies for NDIs with sulfides $(-3.92 \mathrm{eV})$, sulfoxides $(-4.31 \mathrm{eV})$ and sulfones ($4.52 \mathrm{eV}$ ) in the core, at $7{ }^{\circ} \mathrm{C}$. Negative $\Delta \Delta G_{\mathrm{TS}}{ }^{\ddagger}$ indicate selective acceleration of the disfavoured over the favored reaction. conducted at $7{ }^{\circ} \mathrm{C}$ (see $\mathrm{SI}$ ). Increasing selectivity with $\pi$ acidity together with the confirmation of selectivity inversion using control 12 at low temperature $\left(\eta^{\mathrm{d} / \mathrm{f}}=0.7\right)$ were already strong indicators for operational anion-m interactions anologous to the results observed with MHT substrates. Indeed, the use of flexible Leonard turns increased selectivity from $\eta^{\mathrm{d} / \mathrm{f}}=1.4$ for sulfide 9 to $\eta^{\mathrm{d} / \mathrm{f}}=1.9$ for sulfoxide 10 and $\eta^{\mathrm{dff}}=2.1$ for sulfone 11 (Figure 2c, Table 1, entries 23-25). As anticipated, fixed Leonard turns at minimal $\pi$ acidity in $\mathbf{5}$ were as good as flexible turns at maximal $\pi$ acidity in 11 (Table 1, entries 22, 26). Indeed, fixed Leonard turns at maximal $\pi$ acidity in $\mathbf{7}$ afforded a selectivity of $\eta^{d / f}=3.0$ - the highest selectivity! - demonstrating that rigidifying a Leonard turn is equally applicable as a strategy for promoting the successful formation of intrinsically disfavored addition product with $\beta$-keto acids.

Compared to other noncovalent interactions such as hydrogen, halogen or chalcogen bonds in catalysis, ${ }^{[19]}$ interactions with aromatic surfaces are much less directional, thus creating the challenge to ideally place a substrate on such a $\pi$ surface. This study offers a general and practical solution. Currently, we are most interested to apply the lessons learned to other reactions ${ }^{[20]}$ and to more complex systems. ${ }^{[21,22]}$

\section{Acknowledgements}

We thank the NMR and the Sciences Mass Spectrometry (SMS) platforms for services, and the University of Geneva, the European Research Council (ERC Advanced Investigator), the Swiss National Centre of Competence in Research (NCCR) Molecular Systems Engineering, the Swiss NCCR Chemical Biology and the Swiss NSF for financial support. A.-J. A. thanks the US NSF for a GROW Fellowship and the Swiss SERI/FCS for a Government Excellence Scholarship.

Keywords: Anion- $\pi$ interactions - enolates - selectivity catalysis - preorganization

[1] J. Staunton, K. J. Weissman, Nat. Prod. Rep. 2001, 18, 380-416.
[2] Y. Zhao, S. Benz, N. Sakai, S. Matile, Chem. Sci. 2015, 6, 6219-6223.

[3] a) J. Lubkoll, H. Wennemers, Angew. Chem. Int. Ed. 2007, 46, 68416844; Angew. Chem. 2007, 119, 6965-6968; b) Y. Pan, C. W. Kee, Z Jiang, T. Ma, Y. Zhao, Y. Yang, H. Xue, C. H. Tan, Chem. Eur. J. 2011, 17, 8363-8370.

[4] a) D. A. Stauffer, R. E. Barrans Jr., D. A. Dougherty, Angew. Chem. Int. Ed. 1990, 29, 915-918; Angew. Chem. 1990,102, 953-956; b) R. R. Knowles, S. Lin, E. N. Jacobsen, J. Am. Chem. Soc. 2010, 132, 50305032; c) Q. Zhang, K. Tiefenbacher, Nat. Chem. 2015, 7, 197-202.

[5] a) M. Giese, M. Albrecht, K. Rissanen, Chem. Rev. 2015, 115, 88678895 ; b) H. T. Chifotides, K. R. Dunbar, Acc. Chem. Res. 2013, 46, 894-906; c) A. Frontera, P. Gamez, M. Mascal, T. J. Mooibroek, J. Reedijk, Angew. Chem. Int. Ed. 2011, 50, 9564-9583; Angew. Chem. 2011, 123, 9736-9756; d) D.-X. Wang, M.-X. Wang, Chimia 2011, 65, 939-943; e) P. Ballester, Acc. Chem. Res. 2013, 46, 874-884.

[6] a) A. Frontera, F. Saczewski, M. Gdaniec, E. Dziemidowicz-Borys, A. Kurland, P. M. Deyà, D. Quiñonero, C. Garau, Chem. Eur. J. 2005, 11, 6560-6567; b) M. Giese, M. Albrecht, K. Wiemer, A. Valkonen, K. Rissanen, New J. Chem. 2012, 36, 1368-1372; c) M. Giese, M. Albrecht, K. Rissanen, Chem. Commun. 2016, 52, 1778-1795.

[7] a) Q. He, Y.-F. Ao, Z.-T. Huang, D.-X. Wang, Angew. Chem. Int. Ed. 2015, 54, 11785-11790; Angew. Chem. 2015, 127, 11951-11956; b) S. T. Schneebeli, M. Frasconi, Z. Liu, Y. Wu, D. M. Gardner, N. L. Strutt, C. Cheng, R. Carmieli, M. R. Wasielewski, J. F. Stoddart, Angew. Chem. Int. Ed. 2013, 52, 13100-13104; Angew. Chem. 2013, 125, 1333813342.

[8] A. Vargas Jentzsch, S. Matile, J. Am. Chem. Soc. 2013, 135, 53025303.

[9] K. Fujisawa, M. Humbert-Droz, R. Letrun, E. Vauthey, T. A. Wesolowski, N. Sakai, S. Matile, J. Am. Chem. Soc. 2015, 137, 11047-11056.

[10] a) Y. Zhao, Y. Domoto, E. Orentas, C. Beuchat, D. Emery, J. Mareda, N. Sakai, S. Matile, Angew. Chem. Int. Ed. 2013, 52, 9940-9943; Angew. Chem. 2013, 125, 10124-10127; b) A. Berkessel, S. Das, D. Pekel, J.M. Neudörfl, Angew. Chem. Int. Ed. 2014, 53, 11660-11664; Angew. Chem. 2014 126, 11846-11850; c) Y. Zhao, Y. Cotelle, A.-J. Avestro, N. Sakai, S. Matile, J. Am. Chem. Soc. 2015, 11582-11585; d) K. S. Lee, J. R. Parquette, Chem. Commun. 2015, 51, 15653-15656; e) F. N. Miros, Y. Zhao, G. Sargsyan, M. Pupier, C. Besnard, C. Beuchat, J. Mareda, N. Sakai, S. Matile, Chem. Eur. J. 2015, DOI: 10.1002/chem.201504008.

[11] Y. Zhao, C. Beuchat, Y. Domoto, J. Gajewy, A. Wilson, J. Mareda, N. Sakai, S. Matile, J. Am. Chem. Soc. 2014, 136, 2101-2111.

[12] a) S.-L. Suraru, F. Würthner, Angew. Chem. Int. Ed. 2014, 53, 74287448; Angew. Chem. 2014, 126, 7558-7578; b) S. V. Bhosale, C. H. Jani, S. J. Langford, Chem. Soc. Rev. 2008, 37, 331-342.

[13] N. J. Leonard, Acc. Chem. Res. 1979, 12, 423-429.

[14] J. Míšek, A. Vargas Jentzsch, S. I. Sakurai, D. Emery, J. Mareda, S. Matile, Angew. Chem. Int. Ed. 2010, 49, 7680-7683; Angew. Chem. 2010, 122, 7846-7849.

[15] a) I. Richter, J. Minari, P. Axe, J. P. Lowe, T. D. James, K. Sakurai, S. D. Bull, J. S. Fossey, Chem. Commun. 2008, 1082-1084; b) K. Avasthi, A. Ansari, A. K. Tewari, R. Kant, P. R. Maulik, Org. Lett. 2009, 11, 52905293.

[16] J. I. Seeman, Chem. Rev. 1983, 83, 83-134.

[17] F. Zhong, W. Yao, X. Dou, Y. Lu, Org. Lett. 2012, 14, 4018-4021.

[18] H. W. Moon, D. Y. Kim, Tetrahedron Lett. 2012, 53, 6569-6572.

[19] a) S. H. Jungbauer, S. M. Huber, J. Am. Chem. Soc. 2015, 137, 1211012120; b) A. Bauzà, T. J. Mooibroek, A. Frontera, ChemPhysChem 2015, 16, 2496-2517.

[20] Promising preliminary results with other reactions will be reported in due course.

[21] B. Baumeister, N. Sakai, S. Matile, Org. Lett. 2001, 3, 4229-4232.

[22] All chiral anion- $\pi$ catalysts tested performed with negligible enantioselectivity, independent of solvent and temperature $(<7 \%$ ee, not shown). However, preliminary results show that whence integrated into complex systems, catalyst $\mathbf{5}$ can afford $\mathbf{3 a}$ in up to $95 \%$ ee. 


\section{Entry for the Table of Contents}

\section{COMMUNICATION}
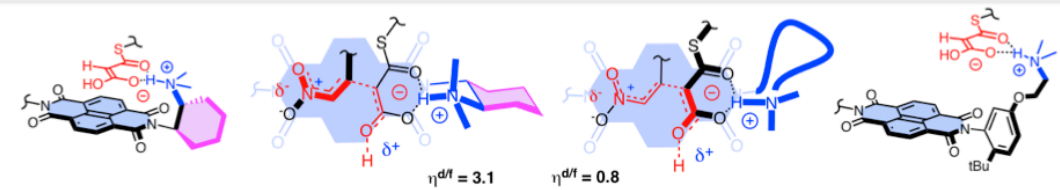

Served on a platter: Most simple, most compact, precisely sculpted Leonard turns are introduced to firmly and reliably place reactions on aromatic surfaces, minimizing entropic costs to maximize enthalpic gains and thus best integrate anion- $\pi$, cation- $\pi$ and ionpair- $\pi$ interactions in catalysis. Significant inversion of selectivity from less desirable decarboxylation with loose turns (right) to more relevant enolate addition pathways on $\pi$-acidic surfaces with rigidified Leonard turns (left) demonstrates the power of the concept.
Yoann Cotelle, Sebastian Benz, AlyssaJennifer Avestro, Thomas R. Ward, Naomi Sakai, Stefan Matile

\section{Page No. - Page No.}

Anion-m Catalysis of Enolate Chemistry: Rigidified Leonard Turns as a General Tool to Run Reactions on Aromatic Surfaces 
Click here to access/download Supporting Information 227 MatileSIv2ach.pdf 


\title{
Anion-m Catalysis of Enolate Chemistry: Rigidified Leonard Turns as a General Tool to Run Reactions on Aromatic Surfaces
}

\author{
Yoann Cotelle, ${ }^{[a, b]}$ Sebastian Benz, ${ }^{[a, b]}$ Alyssa-Jennifer Avestro, ${ }^{[a, c, d]}$ Thomas R. Ward, ${ }^{[e]}$ Naomi Sakai ${ }^{[a]}$ \\ and Stefan Matile ${ }^{[a] *}$
}

\begin{abstract}
To integrate anion- $\pi$, cation- $\pi$ and ionpair- $\pi$ interactions in catalysis, the fundamental challenge is to run reactions reliably on aromatic surfaces. Addressing a specific question concerning enolate addition to nitroolefins, this study elaborates on Leonard turns to tackle this problem in a general manner. Increasingly refined turns are constructed to position malonate half thioesters as close as possible on $\pi$-acidic surfaces. The resulting preorganization of reactive intermediates is shown to support the disfavored addition to enolate acceptors to an absolutely unexpected extent. This decisive impact on anion- $\pi$ catalysis increases with the rigidity of the turns. The new, rigidified Leonard turns are most effective with weak anion$\pi$ interactions, while stronger interactions do not require such ideal substrate positioning to operate well. The stunning simplicity of the motif and its surprisingly strong relevance for function promises general usefulness of the introduced approach.
\end{abstract}

Rien ne sert de courir ; il faut partir à point. Le Lièvre et la Tortue en sont un témoignage.

Thus begins Jean de La Fontaine (1621-1695 AD) to recount the ancient Greek fable from Aesop (620-560 BC). The result is known. In the context of chemical transformations, Aesop's fable perfectly describes the challenge to selectively catalyze a disfavored reaction. A most intriguing example for "tortoise-andhare" catalysis occurs at the beginning of the biosynthesis of most natural products and is repeated most impressively in the polyketide pathway. ${ }^{[1]}$ Malonyl-CoA, a malonic acid half thioester (MAHT), has evolved as the substrate of choice to accomplish the involved enolate chemistry under biological conditions. However, without enzymes under unoptimized conditions in solution, the addition of the conjugate bases of MAHTs such as 1a, i.e., the malonate half thioesters (MHTs), to enolate acceptors such as nitroolefin 2 to cleanly generate the relevant addition product $\mathbf{3 a}$ fails (Figure 1 ). ${ }^{[2]}$ Instead, decarboxylation is

[a] Dr. Y. Cotelle, S. Benz, Dr. A.-J. Avestro, Dr. N. Sakai, Prof. S. Matile Department of Organic Chemistry National Centre of Competence in Research (NCCR) Molecular Systems Engineering

University of Geneva, Geneva, Switzerland

Fax: (+) 41223793215

E-mail: stefan.matile@unige.ch

Homepage: www unige.ch/sciences/chiorg/matile/

[b] These two authors contributed equally to this study.

[c] Dr. A.-J. Avestro

Department of Chemistry, Northwestern University, Evanston IL, USA

[d] Current address: Department of Chemistry, University of Durham, Durham, United Kingdom

[e] Prof. T. R. Ward

Department of Chemistry, NCCR Molecular Systems Engineering University of Basel, Basel, Switzerland

Supporting information for this article is given via a link at the end of the document. the favored reaction, leading to the less useful thioester $\mathbf{4 a}$ as the major product. Several elegant solutions have been developed to tame the capricious MHT anions, including bioinspired approaches to asymmetric enolate addition to various acceptors. ${ }^{[3]}$

a)

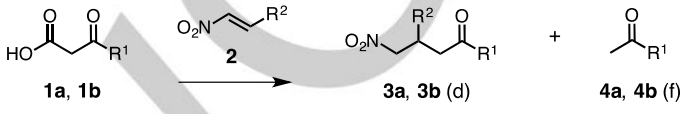

b) d) addition $\uparrow$ decarboxylation $\uparrow$

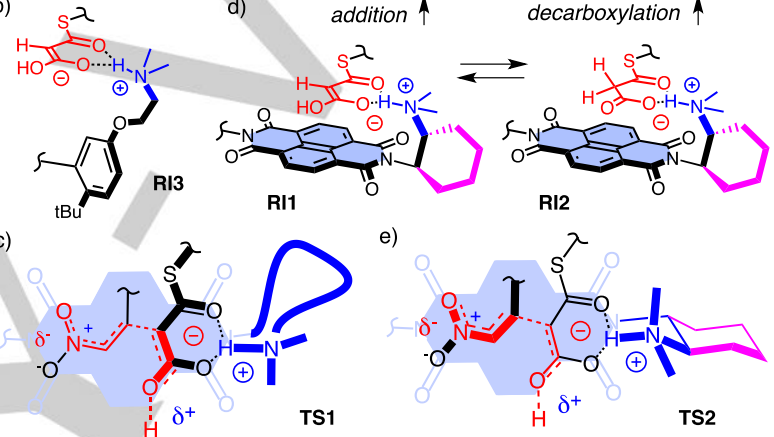

Figure 1. a) Addition of MAHTs $1 \mathrm{a}\left(\mathrm{R}^{1}=\mathrm{SPMP}, \mathrm{PMP}=p\right.$-methoxyphenyl $)$ or $\beta$-keto acids $\mathbf{1 b}\left(\mathrm{R}^{1}=\mathrm{Ph}\right)$ to nitroolefins $2\left(\mathrm{R}^{2}=\mathrm{Ph}\right)$, forming disfavored (d) addition products $\mathbf{3 a} / \mathbf{3 b}$ or the favored (f) decarboxylation products $\mathbf{4 a} / \mathbf{4 b}$. b) The original $m$-phenyl turns place the enolate tautomer far from the $\pi$ surface. c) "Top-down" addition of remote enolates (R/3) to nitroolefins on the $\pi$ surface. d) Fixed (magenta) Leonard turns should place MHTs close to the $\pi$ surface to influence the equilibrium between MHT tautomers. e) "Bottom-up" addition of enolates on the $\pi$ surface (RI1) to nitroolefins far from the $\pi$ surface.

Complementary to the more common cation-m interactions on $\pi$-basic aromatic surfaces, ${ }^{[4]}$ anion- $\pi$ interactions occur on $\pi$ acidic surfaces. Their existence has been proposed by theoreticians a bit more than a decade ago and verified experimentally to occur in solid, solution and gas phase. ${ }^{[5,6]}$ Functional relevance of anion- $\pi$ interactions has been demonstrated for self-assembly, ${ }^{[7]}$ transport ${ }^{[8,9]}$ and, most recently, also for catalysis. ${ }^{[2,10,11]}$ In this context, the selective acceleration of the disfavored addition of MAHT $\mathbf{1 a}$ to nitroolefins 2 has been realized $^{[2]}$ in the presence of naphthalenediimides (NDIs). ${ }^{[10,12]}$ Their $\pi$-acidic surface has been introduced as ideal for differentiating between planar MHT tautomers with delocalized charges (as in reactive intermediate RI1, Figure 1d) and deplanarized tautomers with charges localized on the carboxylate (as in RI2). This discrimination was expected to differently influence the energy of the transition states leading to enolate addition and decarboxylation and thus to control the selectivity of the reaction. However, in our original design, the catalytic amine was positioned quite far from the $\pi$ surface. Ion pairing to the conjugate ammonium cation should also remove the MHT anion from this surface (RI3, Figure $1 \mathrm{~b}$ ), enabling the nitroolefin acceptor 2 on the $\pi$ surface to be approached by the MHT from above or "top-down" (transition state TS1, Figure 1c). This architecture should thus provide 


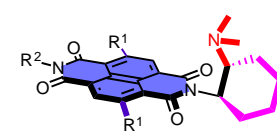<smiles>C1CCC2(C1)CCC[I-]2</smiles>

8

5: $\mathrm{R}^{1}=\mathrm{SEt}$ 6: $\mathrm{R}^{1}=S O E \mathrm{t}$ 7: $\mathrm{R}^{1}=\mathrm{SO}_{2} \mathrm{Et}$

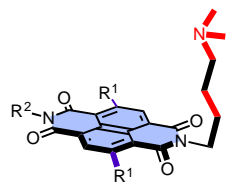

13: $R^{1}=S E t$

14: $R^{1}=S O E t$

15: $\mathrm{R}^{1}=\mathrm{SO}_{2} \mathrm{Et}$
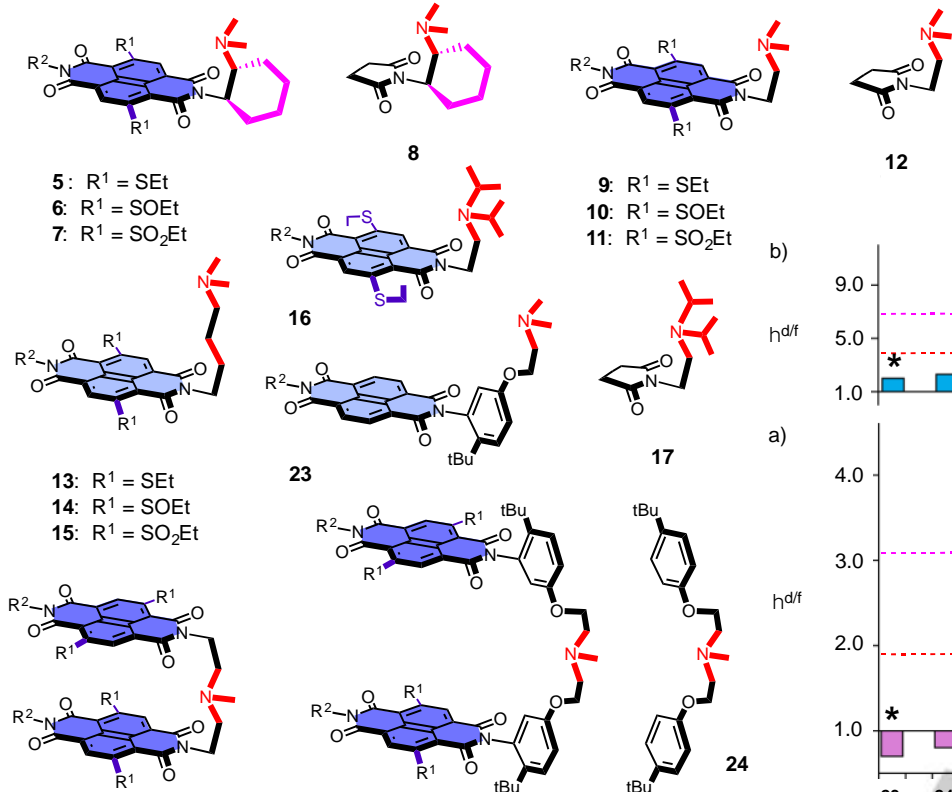

12

9: $\mathrm{R}^{1}=\mathrm{SEt}$

10: $R^{1}=S O E$

11: $\mathrm{R}^{1}=\mathrm{SO}_{2} \mathrm{Et}$

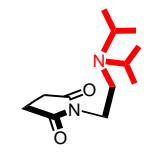

17

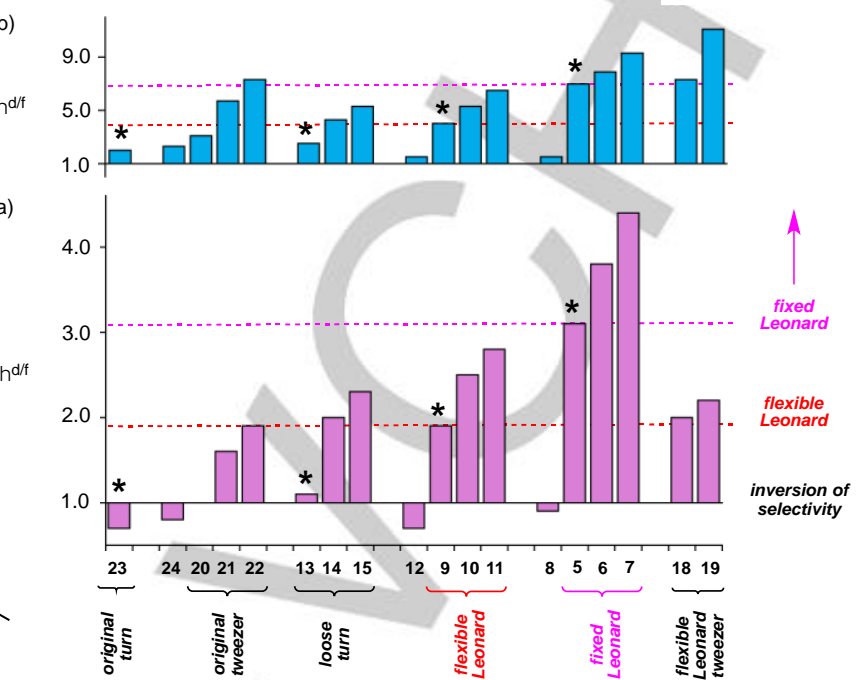

Figure 2. a) Catalyst selectivity $\eta^{\mathrm{d} / \mathrm{f}}=\eta^{\mathrm{d}} / \eta^{\dagger}$, i.e. the yield $\eta^{\mathrm{d}}$ of the intrinsically disfavored product (3a) divided by the yield $\eta^{\dagger}$ of the favored product (4a) in the presence of catalysts $5-24$ in THF- $d_{8}$ at $20 \stackrel{\circ}{\circ}$. b) Same at $7 \stackrel{\circ}{\circ}$ for $3 \mathbf{a}$ and $4 \mathbf{a}$. c) Same at $7 \stackrel{\circ}{\circ}$ for $3 \mathbf{b}$ and $\mathbf{4 b}$. All sulfoxides are isolated as mixtures of stereoisomers. See Table 1 for exact values and conditions. *Most important trends with comparable structures. ${ }^{* *}$ Not measured.

excellent stabilization of nitronate intermediates by anion- $\pi$ interactions albeit having minimal influence on the equilibrium between MHT tautomers, i.e., resulting in poor selectivity. The objective of the present study was to develop general design strategies to enhance selectivity by (i) moving the MHT substrates as close as possible to the $\pi$ surface (Figure 1d), i.e., to have the enolate approach to nitroolefin from below or "bottom-up," and (ii) allowing the nitronate reach the $\pi$ surface only upon its formation during enolate addition (TS2, Figure 1e). The significance of the results described herein suggests that the newly introduced, rigidified Leonard turns ${ }^{[13]}$ represents a general design principle for enabling reactions to occur on aromatic surfaces and thus harnessing the full potential of anion$\pi,,^{[2,5-8,10,11]}$ cation- $\pi^{[4]}$ and ionpair- $\pi$ interaction ${ }^{[9]}$ for catalysis.

The new catalysts and controls 5-19 were designed and synthesized based on lessons learned from the original catalysts 20-24 (Figure 2). Complete details on synthesis and evaluation under standard conditions can be found in the Supporting Information (SI). Anion-m catalyst $\mathbf{9}$ was conceived as starting point for our systematic study. Kept as simple as possible, it contains a single NDI surface with two ethylsulfide substituents as a handle to tune $\pi$ acidity $\left(R^{1}\right),{ }^{[14]}$ an L-leucyl- $n$-hexylamide tail to ensure solubility $\left(R^{2}\right)$, and a Leonard turn in its purest form.

Introduced almost fifty years ago ${ }^{[13]}$ as trimethylene chains, Leonard turns can be considered more generally as three tetrahedral atoms that are in a half-chair conformation and continue with an aromatic surface at one end. The first atom following at the other end will find itself at very short distance literally forced on top of the ipso atom of the aromatic ring. Leonard turns have been used extensively in functional systems, often not explicitly. $[6,9,11,15]$ In catalyst $\mathbf{9}$, the Leonard turn consists of two methylenes and the $s p^{3}$ nitrogen of the amine base. ${ }^{[6]}$ The proton transferred to this nitrogen should then end up at short distance above the imide nitrogen of the NDI, which in turn should place the MHT carbonyls at the positive end of the imide carbonyls, in line with the bonds leading to the naphthalene core (Figures 1d, e).

In view of these considerations, we were delighted to find that, under routine conditions at $20{ }^{\circ} \mathrm{C},{ }^{[2]}$ our first Leonard catalyst 9 catalyzed the addition of MAHT 1a to nitroolefin 2 selectively: The intrinsically disfavored (d) addition product $\mathbf{3} \mathbf{a}$ was obtained in $\eta^{d}=65 \%$ yield, with the naturally more favored (f) decarboxylation product $\mathbf{4 a}$ generated in $\eta^{\dagger}=34 \%$ (Table 1 , entry 5). The resulting selectivity $\eta^{\mathrm{d} / \mathrm{f}}=1.9$ was outstanding considering that the original catalyst $\mathbf{2 3}$ with a loose turn failed to cause the desired selectivity inversion $\left(\eta^{\mathrm{d} / \mathrm{f}}=0.8\right.$, Figure $2 \mathrm{a}^{*}$, Table 1, entry 19). The new Leonard catalyst $\mathbf{9}$, as simple as it gets, was already as good as the most developed original tweezer catalyst $\mathbf{2 2}$, with two NDls next to the amine and two sulfones in the NDI core maximize effective molarity and $\pi$ acidity, respectively (Figure $2 \mathrm{a}$, Table 1, entry 18). Increasing selectivity upon oxidation of the sulfides in the core of 9 to sulfoxides in $\mathbf{1 0}$ and sulfones in $\mathbf{1 1}\left(\eta^{\mathrm{d} / \mathrm{f}}=2.5\right.$ and 2.8) and the absence of selectivity inversion with control 12 without $\pi$ surface $\left(\eta^{\mathrm{d} / \mathrm{f}}=0.7\right)$ evinced operational anion- $\pi$ interactions in the presence of Leonard turns (Figure 2a, Table 2, entries 5-8).

Control 13 with a loose tetramethylene turn failed to perform as good as Leonard catalyst 9 (Figure $2 \mathrm{a}^{\star}$ ). However, increasing selectivity inversion with increasing $\pi$ acidity in 13-15 revealed the existence of tortoise-and-hare anion- $\pi$ catalysis also with looser turns (Table 1, entries 9-11). Control 16 with a bulky Hünig base analog in the Leonard turn performed only slightly better than control 17 without $\pi$ surface $\left(\eta^{\mathrm{d} / \mathrm{f}}=0.9 \mathrm{vs} \eta^{\mathrm{d} / \mathrm{f}}=0.7\right.$, Table 1, entry 12-13), presumably because the steric crowding hinders operational anion- $\pi$ interactions. Inreasing the effective 
molarity of $\pi$ surfaces in tweezer-like Leonard catalysts 18-19 did not improve the outstanding activity of the most simple, most compact monomeric Leonard catalysts 9-11 (Figure 2, Table 1, entries $14-15$ vs $5-7$ ).

Table 1. Characteristics of Anion-m Catalysts and Controls. ${ }^{[a]}$

\begin{tabular}{|c|c|c|c|c|c|c|c|}
\hline & $\mathrm{C}^{[\mathrm{b}]}$ & $\begin{array}{c}\pi \\
\text { acidity }\end{array}$ & $S^{[d]}$ & $\begin{array}{l}\eta^{\mathrm{d} /} \\
\%{ }^{[e]}\end{array}$ & $\begin{array}{l}\eta^{f} / \\
\%^{[f]}\end{array}$ & $\eta^{d / f[g]}$ & $\begin{array}{r}\Delta \Delta G_{\mathrm{Ts}^{\ddagger} /} \\
\mathrm{kJ} \mathrm{mol}^{-1[[]]}\end{array}$ \\
\hline 1 & 5 & + & 1a & $84(74)$ & $12(24)$ & $7.0(3.1)$ & $-3.6(-3.0)$ \\
\hline 2 & 6 & ++ & $1 a$ & $87(77)$ & $11(20)$ & $7.9(3.8)$ & $-3.9(-3.5)$ \\
\hline 3 & 7 & +++ & $1 a$ & $86(80)$ & $9(18)$ & $9.6(4.4)$ & $-4.3(-3.9)$ \\
\hline 4 & 8 & - & $1 a$ & $57(47)$ & $39(52)$ & $1.5(0.9)$ & - \\
\hline 5 & 9 & + & $1 a$ & $78(65)$ & $19(34)$ & $4.1(1.9)$ & $-2.3(-2.3)$ \\
\hline 6 & 10 & ++ & $1 a$ & $80(68)$ & $15(27)$ & $5.3(2.5)$ & $-2.9(-2.9)$ \\
\hline 7 & 11 & +++ & $1 a$ & $84(74)$ & $13(26)$ & $6.5(2.8)$ & $-3.4(-3.4)$ \\
\hline 8 & 12 & - & $1 a$ & $59(43)$ & $40(56)$ & $1.5(0.7)$ & - \\
\hline 9 & 13 & + & $1 a$ & $70(50)$ & $28(47)$ & $2.5(1.1)$ & $-1.2(-1.1)$ \\
\hline 10 & 14 & ++ & $1 a$ & $81(64)$ & $19(32)$ & $4.3(2.0)$ & $-2.4(-2.6)$ \\
\hline 11 & 15 & +++ & $1 a$ & $83(68)$ & $16(30)$ & $5.2(2.3)$ & $-2.9(-2.9)$ \\
\hline 12 & 16 & + & $1 a$ & $73(43)$ & $25(48)$ & $2.9(0.9)$ & $-1.5(-0.6)$ \\
\hline 13 & 17 & - & $1 a$ & $(40)$ & (54) & $(0.7)$ & - \\
\hline 14 & 18 & + & $1 a$ & $87(51)$ & $12(23)$ & $7.3(2.0)$ & $-3.7(-2.6)$ \\
\hline 15 & 19 & ++ & $1 a$ & $89(54)$ & $8(27)$ & $11.1(2.2)$ & $-4.6(-3.4)$ \\
\hline 16 & 20 & + & $1 a$ & $71(50)$ & $23(48)$ & $3.1(1.0)$ & $-1.2(-0.9)$ \\
\hline 17 & 21 & ++ & $1 a$ & $80(59)$ & $14(36)$ & $5.7(1.6)$ & $-2.9(-2.0)$ \\
\hline 18 & 22 & +++ & $1 a$ & $80(59)$ & $11(31)$ & $7.3(1.9)$ & $-3.5(-2.6)$ \\
\hline 19 & 23 & + & $1 a$ & $69(46)$ & $30(54)$ & $2.3(0.8)$ & $-0.7(-0.8)$ \\
\hline 20 & 24 & - & $1 a$ & $60(37)$ & $30(53)$ & $2.0(0.7)$ & - \\
\hline 21 & 5 & + & 1b & 65 & 34 & 1.9 & -2.3 \\
\hline 22 & 7 & +++ & $1 b$ & 74 & 25 & 3.0 & -3.4 \\
\hline 23 & 9 & + & $1 b$ & 59 & 41 & 1.4 & -1.6 \\
\hline 24 & 10 & ++ & $1 b$ & 64 & 33 & 1.9 & -2.3 \\
\hline 25 & 11 & +++ & $1 b$ & 68 & 32 & 2.1 & -2.6 \\
\hline 26 & 12 & - & 1b & 42 & 57 & 0.7 & - \\
\hline
\end{tabular}

[a] Reactions were conducted in THF- $d_{8}$ with $20 \mathrm{~mol} \%$ catalyst and monitored by ${ }^{1} \mathrm{H}$ NMR spectroscopy. [b] Catalysts, see Figure 2 for structures. [c] Qualitative indication for increasing $\pi$ acidity, - = no $\pi$ surface. [d] Substrates; 1a: $200 \mathrm{mM}$ with $2 \mathrm{M} \mathrm{2;} \mathrm{1b}$ $200 \mathrm{mM}$ with $1.5 \mathrm{M} \mathrm{2}$. [e] Yield of intrinsically disfavored products $3 \mathbf{a} / \mathbf{3 b}$ in THF at $7{ }^{\circ} \mathrm{C}$ (in parenthesis: $\eta^{\mathrm{d}}$ at $20^{\circ} \mathrm{C}$ ). [f] Yield of the intrinsically favored products $4 \mathbf{a} / \mathbf{4 b}$ at $7{ }^{\circ} \mathrm{C}$ $\left(20^{\circ} \mathrm{C}\right)$. [g] Selectivity $\eta^{\mathrm{d} / \mathrm{f}}=\eta^{\mathrm{d}} / \eta^{\mathrm{f}}$ at $7^{\circ} \mathrm{O} \mathrm{C}\left(20^{\circ} \mathrm{C}\right)$. [h] Selective catalysis: The difference in Gibbs free energy $\Delta G_{T s}{ }^{\ddagger}$ (catalyst) of the two transition states leading to intrinsically favored (f) and disfavored (d) reaction, calibrated against the nearest control $\Delta G \mathrm{ss}^{\ddagger}(\mathbf{8}, \mathbf{1 2}, \mathbf{1 7}, 24) ; \Delta G \mathrm{~s}^{\ddagger}=-R T \mathrm{nn}\left(\eta^{\mathrm{df}}\right),{ }^{[16]} \Delta \Delta \mathrm{GTs}^{\ddagger}=\Delta \mathrm{GTs}^{\ddagger}$ (catalyst) $-\Delta \mathrm{Grs}^{\ddagger}$ (control). Data for 20-24 are from ref [2].

In catalyst $\mathbf{5}$, the flexible Leonard turn of catalyst $\mathbf{9}$ is rigidified (see TS2 in Figure 1e). In doing so, selectivity inversion increased to $\eta^{\mathrm{d} / \mathrm{f}}=3.1$ (Table 1 , entry 1 ). Increasing $\pi$ acidity in catalysts 6 and 7 further improved activity to $\eta^{\mathrm{d} / \mathrm{f}}=3.8$ and $\eta^{\mathrm{d} / \mathrm{f}}=$ 4.4 (Table 1, entries 2, 3). The $\eta^{\mathrm{d} / \mathrm{f}}=0.9$ for control 8 without $\pi$ surface confirmed that these quite spectacular results originate from maximizing anion- $\pi$ interactions with the rigidified Leonard turn in catalysts 5-7. Comparison over the full series of comparable architectures from original and loose turns in $\mathbf{2 3}\left(\eta^{\mathrm{d} / \mathrm{t}}\right.$
$=0.8)$ and $13\left(\eta^{\mathrm{d} / \mathrm{f}}=1.1\right)$ to flexible Leonard turns in $9\left(\eta^{\mathrm{d} / \mathrm{f}}=1.9\right)$ beautifully illustrate the unique power of fixed Leonard turns in $\mathbf{5}$ $\left(\eta^{\mathrm{d} / \mathrm{t}}=3.1\right)$ to run reactions on $\pi$ surfaces and maximize contributions from anion- $\pi$ interactions to catalysis (Figure $2 \mathrm{a}^{*}$ ). The same trend holds true at maximal $\pi$ acidity, moving from $\eta^{d / f}$ $=2.3$ for loose turns in $\mathbf{1 5}$ to $\eta^{\mathrm{d} / \mathrm{f}}=2.8$ with flexible Leonard turns in 9 and $\eta^{\mathrm{d} / \mathrm{f}}=4.4$ with fixed Leonard turns in 7 .

Reactions run at $7 \stackrel{\circ}{\mathrm{C}}$ instead of $20{ }^{\circ} \mathrm{C}$ gave overall the same trends (Figure 2b). For example, the steady increase from original and loose turns in $23\left(\eta^{\mathrm{d} / \mathrm{f}}=2.3\right)$ and $13\left(\eta^{\mathrm{d} / \mathrm{f}}=2.5\right)$ to flexible Leonard turns in $9\left(\eta^{\mathrm{d} / \mathrm{f}}=4.1\right)$ and fixed Leonard turns in $5\left(\eta^{\mathrm{d} / \mathrm{t}}=7.0\right)$ remained intact (Figure $\left.2 \mathrm{a}^{*}\right)$. Overall higher selectivity was consistent with the notion of strengthened anion$\pi$ interactions at lower temperatures. In this instance, the impact of flexible as well as fixed Leonard turns was less pronounced, whereas the effective molarity of $\pi$ surfaces became more important. For example, loose tweezers $\mathbf{2 2}$ at maximal $\pi$ acidity reached the selectivity of fixed Leonard turns $\mathbf{5}$ at minimal $\pi$ acidity (Figure $2 \mathrm{~b}$ ); at $20^{\circ} \mathrm{C}, \mathbf{2 2}$ was clearly less active than 5 (Figure 2a). Moreover, the overall best performance was found for tweezers 19 with flexible Leonard turns and intermediate $\pi$ acidity $\left(\eta^{d / f}=11.1\right)$, although the fixed Leonard turns in monomeric 7 were almost as good $\left(\eta^{\mathrm{d} / \mathrm{f}}=9.3\right.$, Figure $\left.2 \mathrm{~b}\right)$; at 20 ${ }^{\circ} \mathrm{C}$, 19 was much less active than $\mathbf{7}$, also 5 (Figure 2a). This overall reduced importance at lower temperature suggested that the contributions from flexible and, in particular, fixed Leonard turns are mainly entropic, i.e., a most practical and most significant expression of the classical concept of preorganization.

It has been established previously ${ }^{[2]}$ that a combination of selective deceleration of the intrinsic decarboxylation in favor of accelerating the disfavored addition gives rise to the observed inversion of selectivity. These most intriguing trends were expected to emerge from the ability of anion-m interactions to distinguish the planar MHT enolate as in Rl1 from the nonplanar malonate tautomer as in RI2 (Figure 1d). Assuming a Curtin-Hammett situation where the two classes of tautomers are in rapid equilibrium, the difference in Gibbs free energy $\Delta G_{T S}{ }^{\ddagger}$ of the two transition states leading to addition (d) or decarboxylation ( $f$ ) is determined by the ratio $d / f$ of the products (Table 1). ${ }^{[16]}$ The resulting $\Delta G_{\mathrm{TS}^{\ddagger}}$ of the catalysts were then calibrated against the background contributions of amine bases without nearby $\pi$-acidic surface. The dependence of the obtained $\Delta \Delta G_{T s^{\ddagger}}$ (Table 1 ) on $\pi$ acidity was roughly linear for fixed Leonard turns in 5-7 $(\diamond)$, flexible Leonard turns in 9-11 (ם) and loose turns in 13-15 catalysts (Figure 3, O). The slopes, however, were clearly different. This difference, i.e., steeper slopes for less preorganizing turns, provided corroborative experimental evidence that the significance of flexible and particularly fixed Leonard turns increases with decreasing $\pi$ acidity. This finding was consistent with the increasing importance of Leonard turns observed with increasing temperature (Figure 2a vs $2 b$ ). Therefore, it can be concluded that precisely engineered turns enable efficient anion- $\pi$ catalysis to take place even with relatively weak $\pi$ acidity. If the aromatic surface is strongly electron deficient, anion-m catalysis takes place efficiently even when substrate placement (i.e., the constituent nature of the Leonard link) is less than ideal. 


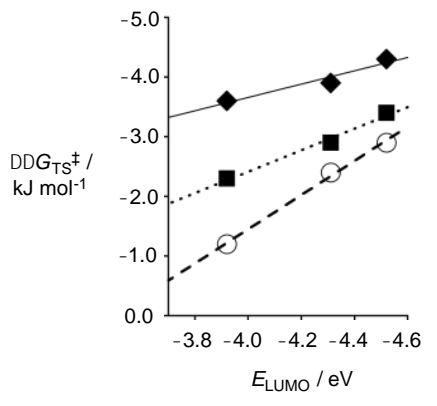

Figure 3. Differential transition-state stabilization $\Delta \Delta G_{T s^{\ddagger}}$ for $\mathbf{5 - 7}(\checkmark$, vs 8$)$ 911 ( $\square$, vs 12) and 13-15 (O, vs 12) as a function of the LUMO energies for NDIs with sulfides $(-3.92 \mathrm{eV})$, sulfoxides $(-4.31 \mathrm{eV})$ and sulfones ($4.52 \mathrm{eV}$ ) in the core, at $7{ }^{\circ} \mathrm{C}$. Negative $\Delta \Delta G_{T s^{\ddagger}}$ indicate selective acceleration of the disfavoured over the favored reaction.

$$
\text { all reactions were }
$$

powerful tool to position a substrate on a m-acidic surface, compatibility with substrates other than MHTs was tested with $\beta$ keto acids $\mathbf{1 b}$ (Figure 1). These substrates readily decarboxylate solution. ${ }^{[17]}$ However, with a suitable catalyst, they too are capable of adding to nitroolefins. ${ }^{[18]} \quad$ Under standard reaction conditions at ambient temperature, it was found that $\quad \beta$-keto acids decarboxylate more rapidly than MHTs. Consequently, conducted at $7{ }^{\circ} \mathrm{C}$ (see $\left.\mathrm{SI}\right)$. Increasing selectivity with $\pi$ acidity together with the confirmation of selectivity inversion using control 12 at low temperature $\left(\eta^{d / f}=0.7\right)$ were already strong indicators for operational anion- $\pi$ interactions anologous to the results observed with MHT substrates. Indeed, the use of flexible Leonard turns increased selectivity from $\eta^{\mathrm{d} / \mathrm{f}}=1.4$ for sulfide 9 to $\eta^{d / f}=1.9$ for sulfoxide 10 and $\eta^{d / f}=2.1$ for sulfone 11 (Figure 2c, Table 1, entries 23-25). As anticipated, fixed Leonard turns at minimal $\pi$ acidity in $\mathbf{5}$ were as good as flexible turns at maximal $\pi$ acidity in $\mathbf{1 1}$ (Table 1, entries 22, 26). Indeed, fixed Leonard turns at maximal $\pi$ acidity in $\mathbf{7}$ afforded a selectivity of $\eta^{\mathrm{d} / \mathrm{f}}=3.0$ - the highest selectivity! - demonstrating that rigidifying a Leonard turn is equally applicable as a strategy for promoting the successful formation of intrinsically disfavored addition product with $\beta$-keto acids.

Compared to other noncovalent interactions such as hydrogen, halogen or chalcogen bonds in catalysis, ${ }^{[19]}$ interactions with aromatic surfaces are much less directional, thus creating the challenge to ideally place a substrate on such a $\pi$ surface. This study offers a general and practical solution. Currently, we are most interested to apply the lessons learned to other reactions ${ }^{[20]}$ and to more complex systems. ${ }^{[1,22]}$

\section{Acknowledgements}

We thank the NMR and the Sciences Mass Spectrometry (SMS) platforms for services, and the University of Geneva, the European Research Council (ERC Advanced Investigator), the Swiss National Centre of Competence in Research (NCCR) Molecular Systems Engineering, the Swiss NCCR Chemical Biology and the Swiss NSF for financial support. A.-J. A. thanks the US NSF for a GROW Fellowship and the Swiss SERI/FCS for a Government Excellence Scholarship.

Keywords: Anion-m interactions - enolates - selectivity catalysis - preorganization

[1] J. Staunton, K. J. Weissman, Nat. Prod. Rep. 2001, 18, 380-416.
[2] Y. Zhao, S. Benz, N. Sakai, S. Matile, Chem. Sci. 2015, 6, 6219-6223.

[3] a) J. Lubkoll, H. Wennemers, Angew. Chem. Int. Ed. 2007, 46, 68416844; Angew. Chem. 2007, 119, 6965-6968; b) Y. Pan, C. W. Kee, Z. Jiang, T. Ma, Y. Zhao, Y. Yang, H. Xue, C. H. Tan, Chem. Eur. J. 2011, 17, 8363-8370.

[4] a) D. A. Stauffer, R. E. Barrans Jr., D. A. Dougherty, Angew. Chem. Int. Ed. 1990, 29, 915-918; Angew. Chem. 1990,102, 953-956; b) R. R. Knowles, S. Lin, E. N. Jacobsen, J. Am. Chem. Soc. 2010, 132, 50305032; c) Q. Zhang, K. Tiefenbacher, Nat. Chem. 2015, 7, 197-202.

[5] a) M. Giese, M. Albrecht, K. Rissanen, Chem. Rev. 2015, 115, 88678895; b) H. T. Chifotides, K. R. Dunbar, Acc. Chem. Res. 2013, 46, 894-906; c) A. Frontera, P. Gamez, M. Mascal, T. J. Mooibroek, J. Reedijk, Angew. Chem. Int. Ed. 2011, 50, 9564-9583; Angew. Chem. 2011, 123, 9736-9756; d) D.-X. Wang, M.-X. Wang, Chimia 2011, 65, 939-943; e) P. Ballester, Acc. Chem. Res. 2013, 46, 874-884.

[6] a) A. Frontera, F. Saczewski, M. Gdaniec, E. Dziemidowicz-Borys, A. Kurland, P. M. Deyà, D. Quiñonero, C. Garau, Chem. Eur. J. 2005, 11, 6560-6567; b) M. Giese, M. Albrecht, K. Wiemer, A. Valkonen, K. Rissanen, New J. Chem. 2012, 36, 1368-1372; c) M. Giese, M. Albrecht, K. Rissanen, Chem. Commun. 2016, 52, 1778-1795.

[7] a) Q. He, Y.-F. Ao, Z.-T. Huang, D.-X. Wang, Angew. Chem. Int. Ed. 2015, 54, 11785-11790; Angew. Chem. 2015, 127, 11951-11956; b) S T. Schneebeli, M. Frasconi, Z. Liu, Y. Wu, D. M. Gardner, N. L. Strutt, C. Cheng, R. Carmieli, M. R. Wasielewski, J. F. Stoddart, Angew. Chem. Int. Ed. 2013, 52, 13100-13104; Angew. Chem. 2013, 125, 13338 13342.

[8] A. Vargas Jentzsch, S. Matile, J. Am. Chem. Soc. 2013, 135, 53025303.

[9] K. Fujisawa, M. Humbert-Droz, R. Letrun, E. Vauthey, T. A. Wesolowski, N. Sakai, S. Matile, J. Am. Chem. Soc. 2015, 137, 11047-11056.

[10] a) Y. Zhao, Y. Domoto, E. Orentas, C. Beuchat, D. Emery, J. Mareda, N Sakai, S. Matile, Angew. Chem. Int. Ed. 2013, 52, 9940-9943; Angew. Chem. 2013, 125, 10124-10127; b) A. Berkessel, S. Das, D. Pekel, J. M. Neudörfl, Angew. Chem. Int. Ed. 2014, 53, 11660-11664; Angew. Chem. 2014 126, 11846-11850; c) Y. Zhao, Y. Cotelle, A.-J. Avestro, N Sakai, S. Matile, J. Am. Chem. Soc. 2015, 11582-11585; d) K. S. Lee, J. R. Parquette, Chem. Commun. 2015, 51, 15653-15656; e) F. N. Miros, Y. Zhao, G. Sargsyan, M. Pupier, C. Besnard, C. Beuchat, J. Mareda, N. Sakai, S. Matile, Chem. Eur. J. 2015, DOI: 10.1002/chem.201504008.

[11] Y. Zhao, C. Beuchat, Y. Domoto, J. Gajewy, A. Wilson, J. Mareda, N. Sakai, S. Matile, J. Am. Chem. Soc. 2014, 136, 2101-2111.

[12] a) S.-L. Suraru, F. Würthner, Angew. Chem. Int. Ed. 2014, 53, 74287448; Angew. Chem. 2014, 126, 7558-7578; b) S. V. Bhosale, C. H. Jani, S. J. Langford, Chem. Soc. Rev. 2008, 37, 331-342.

[13] N. J. Leonard, Acc. Chem. Res. 1979, 12, 423-429.

[14] J. Míšek, A. Vargas Jentzsch, S. I. Sakurai, D. Emery, J. Mareda, S. Matile, Angew. Chem. Int. Ed. 2010, 49, 7680-7683; Angew. Chem. 2010, 122, 7846-7849.

[15] a) I. Richter, J. Minari, P. Axe, J. P. Lowe, T. D. James, K. Sakurai, S. D. Bull, J. S. Fossey, Chem. Commun. 2008, 1082-1084; b) K. Avasthi, A. Ansari, A. K. Tewari, R. Kant, P. R. Maulik, Org. Lett. 2009, 11, 5290-5293.

[16] J. I. Seeman, Chem. Rev. 1983, 83, 83-134.

[17] F. Zhong, W. Yao, X. Dou, Y. Lu, Org. Lett. 2012, 14, 4018-4021.

[18] H. W. Moon, D. Y. Kim, Tetrahedron Lett. 2012, 53, 6569-6572.

[19] a) S. H. Jungbauer, S. M. Huber, J. Am. Chem. Soc. 2015, 137, 1211012120; b) A. Bauzà, T. J. Mooibroek, A. Frontera, ChemPhysChem 2015, 16, 2496-2517.

[20] Promising preliminary results with other reactions will be reported in due course.

[21] B. Baumeister, N. Sakai, S. Matile, Org. Lett. 2001, 3, 4229-4232.

[22] All chiral anion- $\pi$ catalysts tested performed with negligible enantioselectivity, independent of solvent and temperature $(<7 \%$ ee, not shown). However, preliminary results show that whence integrated into complex systems, catalyst $\mathbf{5}$ can afford $\mathbf{3 a}$ in up to $95 \%$ ee. 


\section{Entry for the Table of Contents}

\section{COMMUNICATION}
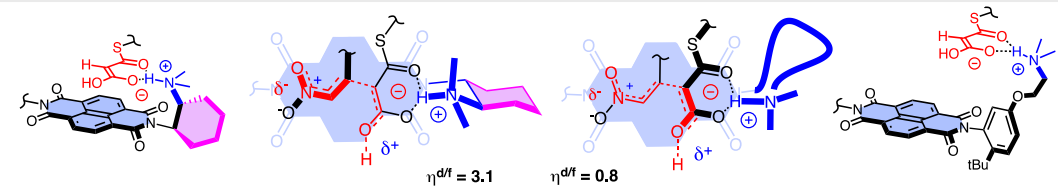

Served on a platter: Most simple, most compact, precisely sculpted Leonard turns are introduced to firmly and reliably place reactions on aromatic surfaces, minimizing entropic costs to maximize enthalpic gains and thus best integrate anion- $\pi$, cation- $\pi$ and ionpair- $\pi$ interactions in catalysis. Significant inversion of selectivity from less desirable decarboxylation with loose turns (right) to more relevant enolate addition pathways on $\pi$-acidic surfaces with rigidified Leonard turns (left) demonstrates the power of the concept.
Yoann Cotelle, Sebastian Benz, AlyssaJennifer Avestro, Thomas R. Ward, Naomi Sakai, Stefan Matile

\section{Page No. - Page No.}

Anion-m Catalysis of Enolate Chemistry: Rigidified Leonard Turns as a General Tool to Run Reactions on Aromatic Surfaces 